Article

\title{
The Unexplored Contribution of Responsible Innovation in Health to Sustainable Development Goals
}

\author{
Pascale Lehoux ${ }^{1,2, *(\mathbb{D}}$, Hudson Pacifico Silva ${ }^{2}\left(\mathbb{D}\right.$, Renata Pozelli Sabio ${ }^{2} \mathbb{D}$ and Federico Roncarolo ${ }^{2}$ \\ 1 Department of Health Management, Evaluation and Policy, University of Montreal, \\ Montreal, QC H3C 3J7, Canada \\ 2 Institute of Public Health Research of University of Montreal (IRSPUM), P.O. Box 6128, \\ Branch Centre-ville, Montreal, QC H3C 3J7, Canada; hp.silva@umontreal.ca (H.P.S.); \\ renata.pozelli.sabio@umontreal.ca (R.P.S.); federico.roncarolo@umontreal.ca (F.R.) \\ * Correspondence: pascale.lehoux@umontreal.ca; Tel.: +1-514-343-7978
}

Received: 6 October 2018; Accepted: 29 October 2018; Published: 2 November 2018

\begin{abstract}
Responsible Innovation in Health (RIH) represents an emerging Science, Technology and Innovation (STI) approach that could support not only the Sustainable Development Goal (SDG) "Good health and well-being" but also other SDGs. Since few studies have conceptualized the relationships between RIH and the SDGs, our goal was to inductively develop a framework to identify knowledge gaps and areas for further reflections. Our exploratory study involved: (1) performing a web-based horizon scanning to identify health innovations with responsibility features; and (2) illustrating through empirical examples how RIH addresses the SDGs. A total of 105 innovations were identified: up to $43 \%$ were developed by non-profit organizations, universities or volunteers; $46.7 \%$ originated from the United States; and $64.5 \%$ targeted countries in Africa, Central and South America and South Asia. These innovations addressed health problems such as newborn care $(15.5 \%)$, reduced mobility and limb amputation (14.5\%), infectious diseases $(10.9 \%)$, pregnancy and delivery care $(9.1 \%)$ and proper access to care and drugs $(7.3 \%)$. Several of these innovations were aligned with SDG10-Reduced inequalities (87\%), SDG17-Partnerships for the goals (54\%), SDG1-No poverty (15\%) and SDG4-Quality education (11\%). A smaller number of them addressed sustainable economic development goals such as SDG11-Sustainable cities and communities (9\%) and SDG9-Industry and innovation (6\%), and environmental sustainability goals such as SDG7-Affordable and clean energy $(7 \%)$ and SDG6-Clean water and sanitation (5\%). Three examples show how RIH combines entrepreneurship and innovation in novel ways to address the determinants of health, thereby contributing to SDG5 (Gender), SDG10 (Inequalities), SDG4 (Education) and SDG8 (Decent work), and indirectly supporting SDG7 (Clean energy) and SDG13 (Climate action). Further research should examine how alternative business models, social enterprises and social finance may support the STI approach behind RIH.
\end{abstract}

Keywords: health technology development; innovation policy; health policy; sustainability; Sustainable Development Goals; Responsible Research and Innovation

\section{Introduction}

In June 2016, a United Nations (UN) multi-stakeholder forum on Science, Technology and Innovation (STI) was held in New York, bringing together more than 600 scientists, innovators, entrepreneurs, technology experts and civil society members from different parts of the world. In its follow-up report, the UN Economic and Social Council defined STI as a lever for achieving the Sustainable Development Goals (SDGs), stressing that "the global community will have the important 
task" of "taking full advantage" of STI, which is central to the advancement of the 2030 Agenda [1]. The Economic and Social Council also recommended that STI "be conceived as means of achieving" the SDGs, not as ends in themselves.

While we agree with the notion that the contribution of STI to sustainable development cannot be overlooked, there is a need to reconsider critically how STI should be supported and organized in order to better support the fulfilment of the 17 SDGs [2]. In the health sector, more particularly, STI approaches that have been established in the past decades and which entail profit-driven and highly capital-intensive ways of producing new technologies not only threaten the sustainability of health systems worldwide, but they also fail to respond to the most pressing population health needs $[3,4]$. Since the 1980s, most OECD countries have organized the financing of their healthcare systems in such a way that "the healthy support the sick, the young support the old, and the rich support the poor" [5]. Nonetheless, it is now clear that health systems also perform better when they are supported by "healthy" public policies in domains that are not directly related to health services but which affect variations in health outcomes such as education, transportation, housing and the environment [6]. These domains are intimately linked to the broader determinants of health [7].

It is within such a broad interdisciplinary perspective that our aim in this article is to explore the ways in which a novel STI approach, called Responsible Innovation in Health (RIH) [8,9], could support not only the SDG3 (Good health and well-being), but also SDGs related to economic development and environmental sustainability. For Silva and colleagues, RIH refers to

a collaborative endeavor wherein stakeholders are committed to clarify and meet a set of ethical, economic, social and environmental principles, values and requirements when they design, finance, produce, distribute, use and discard sociotechnical solutions to address the needs and challenges of health systems in a sustainable way [9].

This definition posits that RIH encompasses social innovations, which aim at creating social change and may benefit health and wellbeing, and sustainable innovations, which aim at reducing environmental harms and may benefit health and wellbeing [10]. More specifically, RIH could, in principle, tap into innovative solutions (SDG9 Industry and innovation) to fulfill SDG3 (Good health and well-being), while addressing concurrently SDGs that encompass determinants of health such as SDG4 (Quality education) or SDG6 (Clean water and sanitation) and SDGs that emphasize environmental concerns such as SDG7 (Affordable and clean energy) or SDG13 (Climate action). We stress "in principle" because although the literature on RIH is growing rapidly, the relationships it entertains with the SDGs remain underexplored. The goal of our study was thus to inductively develop a preliminary framework to help identify key knowledge gaps and areas for further reflections. Because of the current paucity of theoretical and empirical studies on the topic, we adopted an exploratory study design. We applied a problem-oriented STI policy research approach to gather and analyze data stemming from: (1) a web-based horizon scanning that identified health innovations possessing responsibility features; and (2) empirical examples that illustrate how RIH can address SDGs by combining in novel ways entrepreneurship and innovation.

We explain below the novel STI approach that underlies RIH and why the current STI approach limits the emergence of innovations that can support sustainable and equitable health systems. In Section 2, we describe our approach and methodology. In Section 3, after providing descriptive statistics about a large set of health innovations $(n=105)$, we discuss three examples in greater detail and present a framework of the relationships RIH entertains with SDGs. Section 4 highlights the key knowledge gaps this framework emphasizes and suggests further research on how new business models, social enterprises and social finance can support the development of RIH. In Section 5, we conclude on the importance of finding new ways to interface society and STI in the pursuit of the SDGs. 


\section{The STI Approach of Responsible Innovation in Health (RIH)}

According to the UN Economic and Social Commission for Asia and the Pacific, science, technology and innovation are "inextricably connected" even though they refer to different domains of activities [2]. Whereas science refers to the "systematic study of the physical or material world (natural science) and of society (social science)", technology entails the application of scientific knowledge to develop and produce goods or services for practical purposes. Innovation characterizes the novelty or significant improvement of a product, service, process, social organization or commercial method [2].

RIH embodies a novel STI approach that draws on and follows suit to the policy-oriented field of research called Responsible Research and Innovation (RRI). The aim of RRI is "to create a society in which research and innovation practices strive towards sustainable, ethically acceptable and socially desirable outcomes" [11]. RRI shares important affinities with the late 2000s European Union's "Grand Challenges" and with the SDGs. The Grand Challenges fueled "scholarly interest in the role of STI in strategic responses to collective problems" and acknowledged that such challenges were "qualitatively different from traditional STI concerns, often considered under the logic of national systems of innovation geared towards economic growth" [12]. Tackling the Grand Challenges calls for "system transformation" since different actors and perspectives across policy issues and geographical domains have to be mobilized in order to agree on STI solutions [12].

Acknowledging the "inherently complex yet fluid nature" of STI, RRI can contribute to a renewed STI framework for sustainable development, one that: (1) integrates "the social and environmental as well as the economic dimensions of sustainable development"; (2) adheres to "the principles of openness, inclusivity and collaboration"; (3) incorporates "the role of a more diverse range of actors"; and (4) reflects the "regional and global dimensions of STI" [2]. As Spangenberg [13] points out, one should acknowledge that "many sustainability problems have been caused by business activities" and reconsider the role business should play in sustainable development.

Within this perspective, a growing number of RRI scholars recognize that entrepreneurs may deliberately design solutions of greater social and environmental value [14]. From a RRI standpoint, innovation production could be developed and organized in order to remain economically sustainable, to provide shared value and to foster inclusive and sustainable industrial development with stable sources of income and improved work conditions [1]. For Stahl and colleagues, RRI could even have a positive impact on businesses: "the adoption of RRI could help a company develop its links with stakeholders including customers; it could facilitate alignment with societal and regulatory expectations and requirements; and it could improve employee satisfaction" [15]. These potential benefits hinge, however, on the companies' understanding of the principles and implications of RRI and thus on the ability of RRI scholars to adapt their concepts to the context in which these companies operate. Similarly, Lubberink and colleagues encouraged RRI scholars to recognize that commercialization "is an essential stage within the innovation process", one that remains largely shaped by the culture of businesses and the constraints that affect their practices.

Commercially-driven innovation processes differ from those in research due to the priority given to achieving economic impact. Furthermore, the interests and values of innovators in the business context may differ from others (e.g., researchers in academia) and Research and Development departments face different constraints regarding confidentiality and public image [16].

In their review of the literature on RRI in the business context, Lubberink and colleagues observed that efforts to identify whether an innovation had negative implications or could generate additional desirable impacts were "scarce", but a number of companies were already engaging in systems-thinking, seeking to understand the needs of beneficiaries or consumers and discussing with stakeholders ways to remain responsive to important needs [16]. Likewise, Auer and Jarmai, who interviewed CEOs of small and medium-sized enterprises in the Austrian medical device sector, 
underscored that while these entrepreneurs had no prior knowledge of RRI, their enterprises were operationalizing certain aspects of RRI [17].

Therefore, as Figure 1 summarizes, the current literature supports the notion that RRI embodies a novel STI approach that could enable entrepreneurs to address significant societal challenges, including the SDGs. However, further reflections and empirical studies are needed since "there are deep-seated contradictions" that can limit the potential success of RRI as well as its implementation in the business context [15].

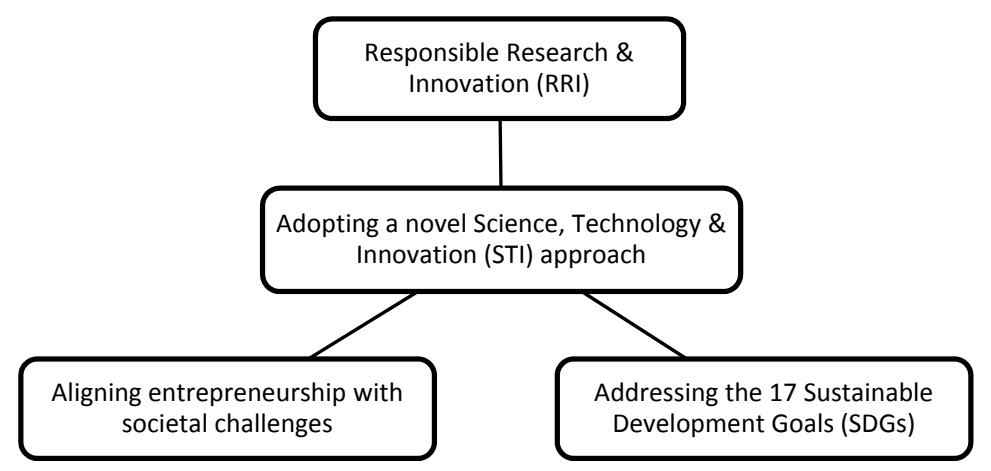

Figure 1. A visual representation of the streams of knowledge on which this paper builds. Source: The authors.

H1.2. Why the Current STI Approach in Health Innovations Needs to Be Transformed

In the health sector, scholars have begun to reconsider the extent to which the STI approach that was established in the 1980s to finance, design and bring to market new drugs and medical devices, is still to be promoted [18-20]. This STI approach increases inequalities and undermines the sustainability of health systems around the world, be they publicly or privately funded $[7,21,22]$. For Fineberg, sustainable health systems should be (1) affordable to patients and families, employers and third-party payers; (2) acceptable to patients and health professionals; and (3) adaptable to new diseases, changing demographics, scientific discoveries and technological innovations [23]. All three characteristics are directly affected and typically constrained by the STI approach of the medical device and pharmaceutical industries, which now both operate on a global scale [24].

The economic contexts in which health innovation took shape during the second half of the 20th century supported shifting dynamics between the demand for, and the supply of innovations [25]. In the 1950s, the post-war economy in industrialized countries contributed to the demand by supporting the development of health systems. As the knowledge gained through military R\&D benefitted STI in the medical sector, the emergence of universal healthcare coverage provided the capacity to pay for these new technologies in industrialized countries. Then, in the 1980s, the growth of health spending entered into conflict with a market economy ideology that imposed budgetary constraints and fiscal austerity in government-led programs. In these years, disparities in access to novel drugs and devices increased within and between countries. To protect equity, "the governments of most OECD countries have become heavily involved in the regulation, financing and sometimes the provision of medical care" since the "problem of reconciling rising demand and increasing costs" mainly fell in the public sector even though private companies were responsible for price increases [5].

This tension between innovation and access represents a thorny issue for health policymakers $[4,26]$. For instance, Sofosbuvir-based medicines with "a US list price of about \$90,000" per 3-month treatment course have recently "challenged government budgets and led to rationing" [27]. By offering cure rates of over $90 \%$, these drugs represent an important breakthrough for patients with hepatitis C infection, which largely affects vulnerable groups such as people who inject drugs or suffer from HIV / AIDS. According to Roy and King [27], "one argument for the high prices has been that the curative drugs represent a major advance in value to patients and health systems" and they are indeed "more cost effective than many expensive medicines that provide only marginal benefit". The company's ability 
to charge high prices relies on its monopoly, while the public sector is paying "twice", it supports STI and then purchases innovative products.

Equity and sustainability challenges also arise because health innovations rely on health services that are labor-intensive, require specialized personnel and are thus concentrated in large urban centers [5]. New health technology often requires substantial infrastructure, which may not exist in many poor countries. Considering that "as many as $50 \%$ of all patients with cancer would be expected to benefit from radiotherapy", the lack of radiotherapy facilities in many countries in sub-Saharan Africa is "particularly troubling" [28]. For Pramesh et al. [29], India faces "a problem common to other emerging and high-income economies" since it struggles with the unsustainable prices of cancer drugs. Even in a rich country like the United States, the difficulty of deploying technologies and qualified personnel to remote and/or rural areas induces significant inequalities in access to basic primary care [30]. MacDonnell and Darzi [31] suggest prioritizing innovations that simultaneously improve outcomes and reduce labor intensity. This includes innovations that support general practitioners, community health and social care providers and the patient's capacity for self-care.

The problems raised by the current STI approach to health innovations are not limited to the healthcare sector. Rather, its socioeconomic underpinnings affect how the SDGs can be fulfilled in rich and poor countries alike: (1) higher unit costs of innovations ultimately result in greater inequalities in access since third-party payers are forced to either increase insurance premiums or engage into rationing; and (2) a greater share of a country's Gross Domestic Product (GDP) spent on healthcare entails a reduced ability to maintain a diversified economy in which the other determinants of health (education, food insecurity, land use, etc.) can be properly addressed. This is troublesome considering that a healthy population represents "a precondition for, an outcome of, and an indicator of" the economic, social and environmental dimensions of sustainable development [32].

Another reason why it is important to critically examine the current STI approach to health innovations lies with the recognition that it is largely driven by speculative investments, where short-term returns prove more important than long-term health gains. Public resources around the world are used to support health technology-based entrepreneurial activities, which remain highly dependent upon venture capital [33]. One must thus consider how capital investors' preferences and financial markets affect the kinds of innovation being introduced in health systems [18,34]. From the investors' standpoint, with an estimated $21.6 \%$ net profit margin, health technology is highly attractive [35]. Lehoux and colleagues observed that capital investors prefer to invest in technologies that are likely to find their "purchaser" swiftly and "do not automatically see value in ventures that address pressing needs unless these ventures can compete as winners in the healthcare "marketplace'" [21]. Innovations that are seen as less risky by venture capitalists are those that address very large and easy to reach markets, that offer to physicians, the means to generate revenues and that will be acquired within a relatively short timeframe by established medical device manufacturers [20]. This short-term logic enables recouping one's investment, but it reproduces the technology creation paradigm that makes health systems unsustainable and produces, ultimately, marginally innovative technologies [36].

Overall, the literature underscores the STI dynamics that contributed to shaping today's health innovation creation paradigm, which threatens the equity and sustainability of health systems. It also highlights the relevance of examining more closely the STI approach that RIH embodies and which could support the fulfillment of SDG3 (Good health and well-being) while concurrently addressing SDGs related to the determinants of health and sustainable economic development.

\section{Approach and Methods}

\subsection{Inductive STI Policy Research Approach}

Because there have been so far very few attempts to conceptualize or empirically examine the relationships between RIH and the SDGs [22,37], we adopted an inductive STI policy research approach. According to Colquitt and Zapata-Phelan, empirical studies that rely on an inductive approach draw 
on existing theory to guide the categorizing of empirical observations, but they "do not include a priori hypotheses as a starting point" [38]. The data gathered in such studies are mainly used to inform the development of "propositions that can be tested in future studies" [38]. For Morlacchi and Martin, STI policy research "is primarily a problem-oriented field" that considers the central role of businesses in the evolution of STI by drawing on social sciences such as economics, sociology, political science or organizational science [39]. Theorizing in STI policy research is mostly inductive, a feature that differentiates the field from other disciplines where theory often "comes first" and the empirical work is performed to test the theory [39].

Following this approach, we gathered and analyzed empirical data and examples to develop a preliminary framework of the relationships between RIH and the SDGs that could help to identify key knowledge gaps and areas for further reflections. Our empirical investigation was embedded within a broader research project that was aimed at developing a tool to assess the degree of responsibility of health innovations [9]. Relying on a horizon scanning methodology, we created an inventory of innovations that possessed certain responsibility features in order to identify and organize the more generic dimensions and attributes the tool had to include.

\subsection{Web-Based Horizon Scanning}

As an exploratory research method, horizon scanning has found a particular niche in STI since it helps to support policy development around emerging innovations. Horizon scanning may pursue an "alerting function" in order to help policymakers to anticipate emerging issues or threats, or a creative function in order to contribute to opening up new policy options [40]. In the field of Health Technology Assessment (HTA), horizon scanning is performed periodically to identify potentially significant technologies that may become available on the market within the next 5 years [41]. To identify these technologies, a combination of sources is recommended since it increases the usefulness of the information and its likely accuracy [41].

To fulfill our study's aim, we followed the methodological principles applied in HTA and performed a social media horizon scanning that was supplemented by targeted searches on dedicated websites. Our assumption was that a large number of responsible innovations may not yet be reported in the scientific literature, but could be identified through social media platforms such as Twitter, Reddit, Facebook, LinkedIn and Instagram [42]. We thus iteratively retrieved and analyzed information from a variety of digital sources following the distinction made by Palomino and colleagues between searching and scanning: "in the case of searching, what is likely to be interesting must be known before it is sought, whereas in the case of scanning, the interest is judged after retrieval" [43]. These two types of activity are in fact complementary since an issue-centered scanning approach starts with a number of criteria that are gradually refined [40].

Because digital sources addressing a similar topic are closely interconnected (in terms of contents and hyperlinks), a "snowball sampling" of the most relevant websites is recommended [43]. We began with social media accounts and websites that were familiar to our team members and the sample rapidly expanded until saturation where new sources did not yield novel innovations. Key sources were either focused on health innovations (Hinnovic blog, Innovation Countdown 2030, PATH) or on societal challenges (various chapters of the Grand Challenges, Appropedia, Index Awards, Not impossible, SilverEco). Our searches, which took place between May and August 2016, used key words reflecting responsibility features that could qualify the innovative product (e.g., affordability, accessibility, appropriateness, eco-responsibility), its purposes (e.g., equity, sustainability) and the processes by which it was developed (e.g., inclusiveness, responsiveness, openness). Aiming to capture innovations from a large number of countries, these searches were repeated using the same key words in English, French, Spanish and Portuguese (the languages spoken by our team members). Two team members independently categorized $20 \%$ of the innovations retrieved in order to develop consistent inclusion and exclusion criteria, which were then applied by one team member to the remaining sample. We excluded innovations that relied mainly on software (e.g., apps) or mainly on human 
intervention (e.g., clinical or educational approaches) to provide an individualized solution to the user since our tool is meant to assess innovations that include technical components to address the social determinants of health [9].

\subsection{Data Analyses}

We captured on a login/password-secured website images, brief descriptions and technical documentation about the innovations found $(n=105)$. We also collected in an Excel spreadsheet data about the country of origin, the target region, the medical indications for these innovations and the SDGs they addressed. We searched for and downloaded, when available, peer-reviewed publications pertaining to these innovations as well as other sources of information such as reports produced by independent organizations and technical documentation. All this material was used to inform regular discussions among team members about the key responsibility features these innovations shared (or not). Gradually, we focused our attention on the ways in which these innovations addressed (or not) sustainable development challenges and may contribute directly or indirectly to various SDGs.

This is the point at which our iterative strategy turned back to the literature [38]. Like Lubberink and colleagues, we observed that the literature on business considerations of social, frugal and/or sustainable innovation was very informative [16]. It enabled us to develop a framework that gradually became more consistent as we more closely examined the similarities and differences between the 105 innovations. In the next section, after providing descriptive statistics about the sample as a whole, we discuss in greater detail three innovations that are sufficiently diverse (in terms of function, region, target population, business model, etc.) to illustrate key relationships between RIH and the SDGs.

\section{The Relationships RIH Entertains with the SDGs}

\subsection{An Overview of Health Innovations with Responsibility Features}

A total of 105 innovations were identified through the horizon scanning: 69\% of them were at an advanced stage of development (i.e., available for use), $28 \%$ at an intermediary stage (i.e., functionalities or production processes not finalized) and $3 \%$ at a very preliminary stage (i.e., in the form of a prototype). Among the 105 innovations, 57\% had been developed by for-profit organizations, 24\% by non-profit organizations, $15 \%$ by universities, $3 \%$ by hospitals and $1 \%$ by a large network of volunteers.

Table 1 indicates the countries of origin of these innovations. It shows that close to half $(46.7 \%)$ originate from the United States, $16.2 \%$ from Canada and 10.5\% from the United Kingdom. These results need to be interpreted with caution since Internet-based searches are known to produce different hits depending on one's location and Internet search attributes (e.g., language, type of browser, IP address, etc.). It is nonetheless interesting to observe that both India and Brazil are part of the listed countries. This is compatible with the sustainable development principle of supporting domestic technology development.

Table 1. Country of origin of the innovations identified through our horizon scanning.

\begin{tabular}{ccc}
\hline Country of Origin & $\mathbf{n}$ & $\mathbf{\%}$ \\
\hline United States & 479 & 46.7 \\
Canada & 17 & 16.2 \\
United Kingdom & 11 & 10.5 \\
India & 7 & 6.7 \\
Norway & 3 & 2.9 \\
Brazil & 3 & 2.9 \\
France & 2 & 1.9 \\
Others $^{1}$ & 13 & 12.4 \\
\hline Total & $\mathbf{1 0 5}$ & $\mathbf{1 0 0}$
\end{tabular}

1 Argentina, Austria, Belgium, Botswana, Burkina Faso, Spain, Global community, Israel, New Zealand, Uganda, The Netherlands, Peru, Switzerland, Thailand. 
Table 2 shows the geographical regions explicitly targeted by the 105 innovations. While $11.3 \%$ of the innovations were developed to be used worldwide, the large majority $(64.5 \%)$ was targeted at users located in Africa (22.6\%), South Asia (17.7\%), low-income countries (13.7\%) and Central and South America (10.5\%). Very few of these innovations aimed to address health problems in North America (5.6\%), Europe (3.2\%) or Australia (0.8\%). This is not entirely surprising, but it underscores the lack of responsiveness of the established STI model in developed countries.

Table 2. Regions targeted by the innovations.

\begin{tabular}{ccc}
\hline Target Region & N & \% \\
\hline Africa & 28 & 22.6 \\
South Asia & 22 & 17.7 \\
Unspecified & 18 & 14.5 \\
Low income countries & 17 & 13.7 \\
Global & 14 & 11.3 \\
Central and South America & 13 & 10.5 \\
North America & 7 & 5.6 \\
Europe & 4 & 3.2 \\
Australia & 1 & 0.8 \\
\hline Total & $\mathbf{1 2 4}$ & $\mathbf{1 0 0}$
\end{tabular}

Note: The total is larger than 105 since more than one region could be targeted by one innovation.

We extracted information about the types of health problem addressed by the 105 innovations. Table 3 indicates that a large portion of these innovations are targeted at health issues that are prevalent in developing countries such as newborn care (15.5\%), reduced mobility and limb amputation $(14.5 \%)$, infectious diseases $(10.9 \%)$ and pregnancy and delivery care $(9.1 \%)$. One may also note that a fair number of these innovations address the challenge of ensuring proper access to care and drugs $(7.3 \%)$ or the needs of chronically ill patients who suffer from cardiovascular diseases (3.6\%) or cancer $(2.7 \%)$, which are becoming more prevalent in poor countries.

Table 3. Health indications of the innovations.

\begin{tabular}{ccc}
\hline Indication & $\mathbf{N}$ & $\mathbf{\%}$ \\
\hline New-born complications & 17 & 15.5 \\
Reduced mobility \& limb amputation & 16 & 14.5 \\
Malaria, infectious diseases \& diarrheal diseases & 12 & 10.9 \\
Pregnancy \& delivery complications & 10 & 9.1 \\
Visual \& hearing dysfunctions & 9 & 8.2 \\
Tuberculosis \& respiratory diseases & 8 & 7.3 \\
Access to care \& drugs & 8 & 7.3 \\
HIV/AIDS & 7 & 6.4 \\
Cardiovascular diseases & 4 & 3.6 \\
Cancer & 3 & 2.7 \\
Anemia & 2 & 1.8 \\
Diabetes & 2 & 1.8 \\
Other ${ }^{1}$ & 12 & 10.9 \\
Total & $\mathbf{1 1 0}$ & $\mathbf{1 0 0}$
\end{tabular}

Note: The total is larger than 105 since more than one indication could be addressed by one innovation. ${ }^{1}$ Burns, adverse events, epilepsy, hemorrhage due to violence, feminine hygiene, infections, musculoskeletal, gastrointestinal, obesity, parasites, upper limb tremors, care network.

Table 4 shows the distribution of the SDGs addressed by the 105 innovations. By "addressed", we do not mean that the innovation fulfilled a given SDG, but that its responsibility features (in terms of product, development processes or purposes) were aligned with this SDG. In order to emphasize the most important SDGs for RIH, we identified a maximum of five SDGs for each innovation, which 
necessarily included SDG3-Good health and wellbeing. Table 4 indicates that the innovations were more frequently aligned with SDG10-Reduced inequalities (87\%), SDG17-Partnerships for the goals (54\%), SDG1-No poverty (15\%) and SDG4-Quality education (11\%). A smaller number of innovations addressed SDGs that emphasize sustainable economic development such as SDG11-Sustainable cities and communities (9\%) and SDG9-Industry and innovation (6\%). The same observation applies to environmental sustainability goals such as SDG7-Affordable and clean energy (7\%), SDG6-Clean water and sanitation (5\%) and SDG 15-Life on land (2\%).

Table 4. Distribution of the SDGs addressed by the innovations.

\begin{tabular}{lcc}
\hline \multicolumn{1}{c}{ Sustainable Development Goal } & N & \% \\
\hline SDG3. Good health \& well-being & 105 & 100 \\
SDG10. Reduced inequalities & 91 & 87 \\
SDG17. Partnerships for the goals & 57 & 54 \\
SDG1. No poverty & 16 & 15 \\
SDG4. Quality education & 12 & 11 \\
SDG11. Sustainable cities \& communities & 9 & 9 \\
SDG7. Affordable \& clean energy & 7 & 7 \\
SDG9. Industry, innovation \& infrastructure & 6 & 6 \\
SDG6. Clean water \& sanitation & 5 & 5 \\
SDG5. Gender equality & 3 & 3 \\
SDG15. Life on land & 2 & 2 \\
SDG2. Zero hunger & 1 & 1 \\
SDG8. Decent work \& economic growth & 1 & 1 \\
SDG12. Responsible consumption \& production & 1 & 1 \\
SDG13. Climate action & 1 & 1 \\
SDG14. Life below water & 1 & 1 \\
SDG16. Peace, justice \& institutions & 0 & 0 \\
\hline
\end{tabular}

Note: An innovation could be aligned with a maximum of 5 SDGs.

Figure 2 shows the extent to which the innovations could be aligned with multiple SDGs. It is striking that only a very small portion (5\%) of the innovations addressed only one SDG, that is, SDG3-Good health and wellbeing. Close to a third (27\%) of the innovations addressed two SDGs. The fact that a large portion (41\%) addressed three SDGs and that a small yet sizeable number addressed four SDGs (16\%) and five SDGs (11\%) underscores the potential RIH holds for consolidating the SDGs. Below, to illustrate in greater detail how RIH may build on the novel STI approach presented above and contribute, directly or indirectly, to the SDGs, we present three contrasting innovations from the sample.

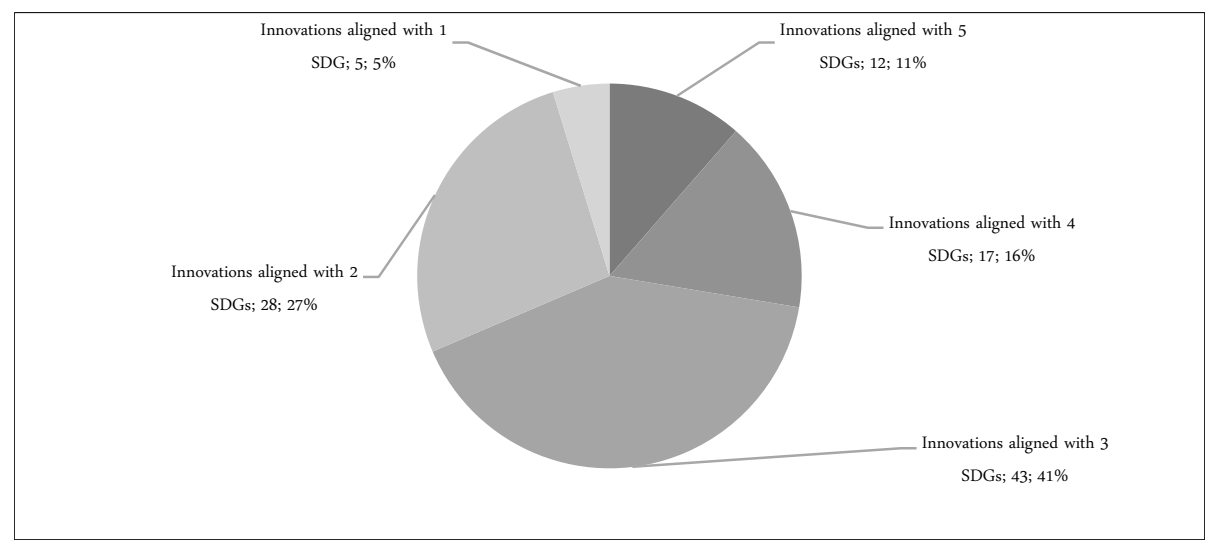

Figure 2. Distribution of the innovations addressing multiple SDGs.

\subsection{Three Examples}

The first innovation highlights how user-driven innovations can address the social determinants of health as well as one key health system challenge in developed countries. In Canada, like in other 
industrialized countries, formal health services are struggling to meet the needs of a growing elderly population. As a result, more than $80 \%$ of Canadians offer unpaid voluntary health and social care assistance to family or community members $[44,45]$. The innovation is an online platform developed to support communication and coordination of the network of caregivers who attend to a vulnerable person. It can be used to archive documents, share news and photos, and synchronize a calendar with caregivers, family and friends. It can be used by both individuals and institutions since the platform can be adapted on demand to meet the needs of its users. For example, the technology was purchased by Saint Elizabeth Healthcare, Canada's largest non-profit nursing service providers. While its use requires electronic hardware such as a computer, smartphone or tablet, it is offered free of charge to all Saint Elizabeth Healthcare clients. The company that developed the platform obtained a "B Corporation" certification, which requires examining carefully the impact of its decisions on employees, suppliers, community, customers and the environment. Considering that there is "no structured way for a company to evaluate the degree to which its practices align with RRI", this example supports the importance of incentive structures [15].

This first example thus highlights that innovation in health does not only aim at SDG3 (Good health and well-being), but can wisely mobilize SDG9 (Industry and innovation) to address important health system-level challenges. It also shows that entrepreneurs may deliberately choose to adopt and maintain responsible corporate behaviors when governance and accountability frameworks such as the B Corporation are made available and are valued by customers and employees.

A second example illustrates how RIH could contribute to both SDG5 (Gender equality) and SDG4 (Quality education) and may have long-term effects contributing to SDG13 (Climate action). Menstrual hygiene is an important issue in parts of the world where women do not have access to sanitary products because of cost or unavailability. A company developed a menstrual cup, which is distributed with the help of philanthropic organizations and through a "buy one, give one" business model: It is made freely available to those who need it in East Africa. This business orientation is aligned with research showing that socially-oriented entrepreneurs may be able to address sustainable development issues in a more comprehensive manner than large companies, but may concurrently have to rely on donors and/or initial public funding in the early stages of their journey [37]. The initial cost of the menstrual cup is 40 dollars, that is equivalent to 5 or 6 months of use of conventional products such as sanitary napkins or tampons. However, the cup has a lifespan of 10 years, which reduces the overall cost by $95 \%[46,47]$. Access to sanitary products is essential because without them millions of women around the world miss school or work days or use unsafe alternatives that may trigger infections. It is estimated that girls can lose up to $20 \%$ of their school year due to a lack of access to sanitary products [47]. As of 2017, the company distributed menstrual cups to more than 24,000 women in East Africa through its redistribution program and field agencies [47]. The product is generally well accepted, but may be less culturally appropriate in some circumstances [46]. On average, a woman will use over 11,000 disposable sanitary products during her reproductive life, which is equivalent, for example, to 200,000 tons of waste each year in the United Kingdom [48].

Hence, this second example relies on an innovative business model that seeks to provide more value to purchasers, users and society and a responsive solution that incorporates climate action (SDG13), gender equity (SDG5) and educational concerns (SDG4).

The third example illustrates how RIH may tackle SDG10 (Reduced inequalities), contribute to SDG1 (No poverty) and be aligned with both SDG7 (Affordable and clean energy) and SDG8 (Decent work). A Brazilian company provides hearing aids that use solar-powered rechargeable batteries at $20 \%$ of the market cost. Its mission is to break the vicious circle of poverty in which deaf children are born and raised. The innovation was initially developed in Botswana where the price of a battery with a 1-week lifetime is $\$ 1$ and where average revenues are between $\$ 1.25$ and $\$ 2.50 /$ day [49]. The rechargeable batteries cost around \$2.50 and last 2-3 years. Although such frugal innovations may prove "ecologically sustainable in a local context", it remains difficult to estimate their efficient use of materials from a product life-cycle perspective [37]. Knowing that 200 million 
disposable batteries are discarded annually, the solar charger reduces the negative environmental impacts associated with hearing aids. The manufacturer also recruits people with a handicap, which, from a public health standpoint, represents an important asset since it enables a vulnerable group to earn stable revenues and thus improve their overall health. This business decision hence goes beyond "traditional" corporate social responsibility activities such as social marketing campaigns or cooperation with NGOs to donate goods to economically vulnerable people [37].

This third example thus shows that health innovation entrepreneurs can develop an affordable and less environmentally harmful product (SDG7) as well as create an enterprise that, by design, pursues a societal mission in a holistic manner. The latter does not only "do good", but it relies on business dynamics to concurrently address several SGDs. It illustrates how STI can be mobilized to tackle key determinants of health by providing vulnerable groups with decent work opportunities (SDG8).

\subsection{A Preliminary Framework of the Potential Relationships between RIH and the SDGs}

Figure 3 summarizes the relationships between RIH and the SDGs that were inductively identified by examining innovations that reflect the purposes, processes or products of RIH as well as examples that seek to tackle multiple SDGs. At the core of this Figure lies the notion that RIH, as an emerging STI model, builds on SDG9 (Industry and innovation) to provide a broad set of solutions to positively affect SDG3 (Health and well-being). This Figure then positions RIH along three axes: its purposes, approaches and long-term impacts.

First, at the top of this Figure are located the SDGs that form important purposes for RIH. This group of SDGs underscores how RIH could address several key determinants of health: It may contribute to SDG1 (No poverty), SDG2 (Zero hunger), SDG4 (Quality education), SDG5 (Gender equality), SDG6 (Clean water and sanitation) and SDG10 (Reduced inequalities). This principle is compatible with recent findings from Strezov and colleagues [32] for whom "public health may be the single most important overarching precondition of sustainable development".

Second, on the left of the Figure are located the SDGs that are related to the STI approaches that RIH can mobilize. If appropriate business models, governance structures and human resources strategies are set in place, the STI approaches underlying RIH may support SDG8 (Decent work and economic growth), SDG12 (Responsible consumption and production), SDG16 (Peace, justice and institutions) and SDG17 (Partnerships for the goals). As we further discuss in the next section, for these SDGs to be supported, one needs to recognize that moving towards RIH cannot be achieved by a small set of innovators. Rather, such a shift requires institutional transformations that support new STI approaches and new types of STI partnerships.

Third, considering that certain health innovations may be designed, manufactured and disposed of by taking energy efficiency, reduced waste and end-of-life solutions into account, RIH could, in the long-run, generate impacts that are aligned with SDG7 (Affordable and clean energy), SDG11 (Sustainable cities and communities), SDG13 (Climate action), SDG14 (Life below water) and SDG15 (Life on land). Though we found only a few innovations that addressed the welfare of non-humans (e.g., replacing animal models in biomedical research by computational solutions), this vision is consistent with the emerging literature on the "one health" concept and the planetary health approach [50]. According to the report of the Rockefeller Foundation-Lancet Commission on planetary health, the advent of the SDGs represents an important opportunity to "tackle health, social, and environmental challenges in an integrated way" [50]. Not only are human and animal health closely connected but "the landscape, ecosystems, and the biodiversity they contain can be managed to protect natural systems, and indirectly, reduce human disease risk" [50].

Given its preliminary nature, the framework should be interpreted in view of the descriptive statistics we presented above, which suggest that many solutions are being developed to address multiple SDGs. The innovations we identified were typically developed in industrialized countries and are meant to be used in resource-poor settings [4,7,22]. Nonetheless, we identified innovations from India and Brazil and one may expect that in the coming decades the number of innovations from 
emerging economies will significantly transform the health innovation landscape [26]. This is likely to include frugal innovations developed for the local needs of low- and middle-income countries [37] as well as adaptation of such innovations to the needs of rich countries [51]. The framework should also be interpreted keeping in mind that the three examples we discussed are not without limitations. They illustrate how entrepreneurs may deliberately choose to develop innovations that are better aligned with the common good. Ostrom argued that individuals are more likely to create and conserve common resources when they have credible and reliable information about the pros and cons of various options and "when they have an opportunity to decide the rules of the game" [52]. RIH is likely to operate according to entrepreneurial rules that differ from the rules of the game already in place, in particular, those prevalent in the highly financialized pharmaceutical and medical device industries $[19,24]$. The fact that up to $43 \%$ of the innovations we inventoried were developed by non-profit organizations, universities or volunteers, lends support to this hypothesis.

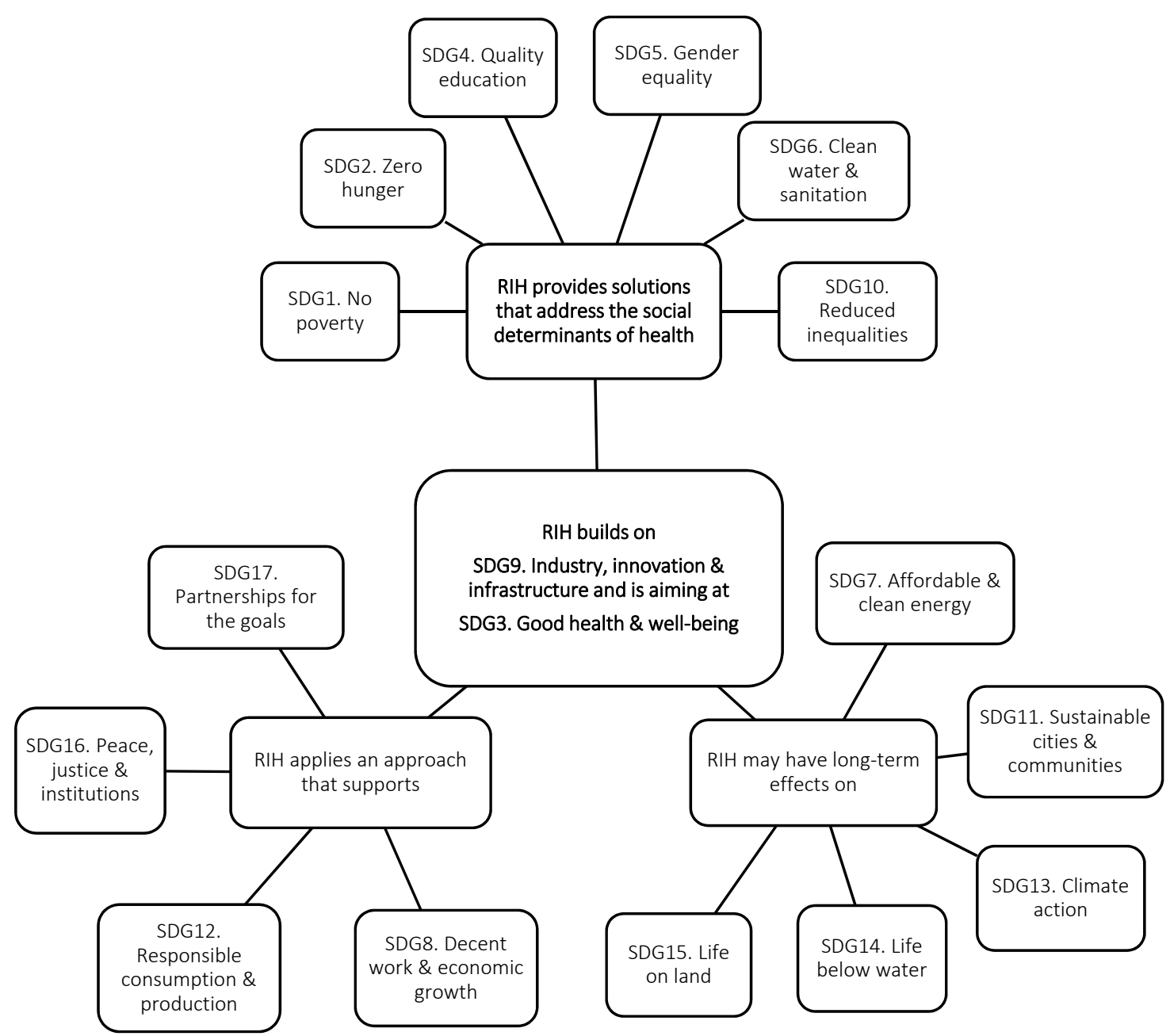

Figure 3. A preliminary framework of the relationships RIH may entertain with the SDGs. Source: The authors.

\section{Key Knowledge Gaps and Areas for Further Reflections}

\subsection{Knowledge Gaps}

While there is a lack of research on the business and financial strategies that can bring responsible innovations to the market $[16,53,54]$, our findings indicate that socially-oriented enterprises are relevant players in RIH and sustainable development. According to Mendell [55], definitions of social entrepreneurship vary between and within countries, but they confirm the existence of a "hybrid 
organizational form that combines social and economic objectives in new ways". What makes social entrepreneurship different from entrepreneurship tout court lies in its mission [56]. A social enterprise is structured to deliver blended value, i.e., social and economic [57-59]. Our findings suggest that social enterprises are well positioned to engage in an STI model wherein "the value created accrues primarily to society as a whole rather than private individuals" [60]. Such a view on value creation "puts a great deal of weight on the difference between social and private problems to be solved" and "the social and private value created as a consequence of novel solutions" [60]. This view also begs the question of the normative orientation of RRI, which aims to transform the governance of STI and, ultimately, the current political and socioeconomic system [16]. For Lubberink and colleagues, alternative approaches to innovation such as social entrepreneurship can bring a relevant contribution to RRI but would be fraught with normative tensions:

Social entrepreneurship and social innovation are anything but value-free, and have politically significant judgments of what the world should look like, and the role that innovation plays in this. Following from responsible innovation, one would suggest that in these alternative approaches to innovation, stakeholders should also be able to negotiate the terms of their inclusion and deliberation, including the politics behind these novel systems, and the substantive biases that can exist [16].

Although we agree that RRI and social entrepreneurship are not value-free, the same observation applies to traditional for-profit organizations. What scholars need to better understand is what organizational forms are, in practice, better able to fulfill which SDGs and through what kinds of partnership. Large companies active in sustainable development indeed tend to partner with non-governmental or not-for-profit organizations when certain market segments are less profitable [37]. While we do not exclude the possibility for traditional for-profit organizations to support RIH, further research should examine the role of alternative business models, and hybrid organizational forms such as social enterprises and social finance in the design, financing, production and commercialization of RIH.

Along these lines, three key knowledge gaps stand out (see Figure 4):

- Gap 1: Identifying what alternative business models fit with sustainable and equitable health systems and what makes such business models better adapted to RIH;

- Gap 2: Identifying the organizational capacity needed by social enterprises to design and commercialize RIH, the risks these enterprises face and how the blended value (i.e., social and economic) they generate responds to health system-level challenges;

- Gap 3: Clarifying under what conditions social finance provides technology-based ventures with the resources and conditions they need to design and commercialize RIH, what metrics may be used to appraise their social and economic returns and what milestones are appropriate to track their progress.

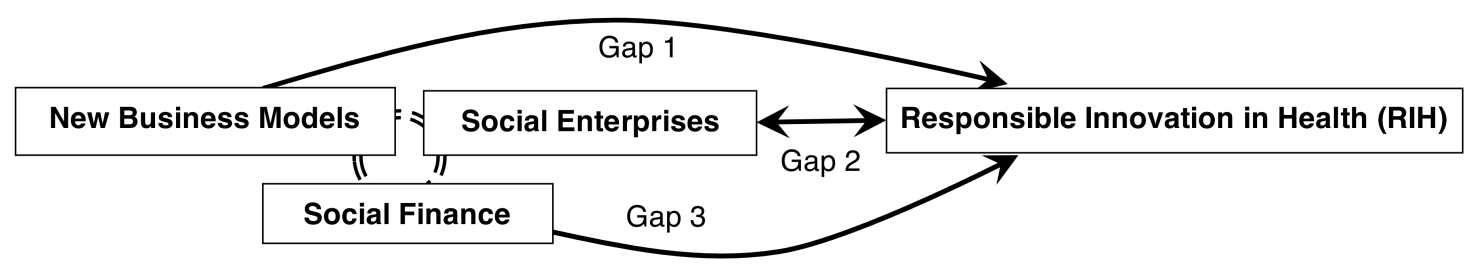

Figure 4. Constructs of interest for further research on RIH and key knowledge gaps. Source: The authors.

\subsubsection{Alternative Business Models and RIH}

For Chesbrough and Rosenbloom [61], a business model is a dynamic entity that "mediates between technology development and economic value creation". The process begins with identifying a value proposition "latent" in the new technology. Entrepreneurs can in principle exploit a large 
spectrum of latent attributes, but they have to ponder how they will respond to the expectations of stakeholders who do not have the same weight in the development process. They include health and social care providers, patients and third-party payers to whom value is offered (i.e., clinical benefits) and investors for whom value is captured (i.e., returns on investment). To respond to investors' concerns and generate revenues faster, those who design technology are often pressured to redefine who the key users are and what latent attributes matter, thereby ending up with an innovation that is sellable, but whose added value may prove marginal from a health policy standpoint [20]. Investors and entrepreneurs may find it difficult to agree on and articulate all the components of a business model. For example, what should be the revenue model of a venture that provides home monitoring for the chronically ill? How does one monetize the value of what this technology prevents from occurring such as unnecessary emergency room visits and hospitalizations?

Since new business models "should be tested and encouraged, especially in areas of public health concern" [27], it is important to identify what alternative business models are better adapted to RIH by building on the business model innovation literature [62,63]. Considering the challenges health systems face, this would entail, for instance, an alignment between value capture and system-level benefits, and between market segment and health inequalities. Scholars should also examine the extent to which "collaborative business modelling" may improve organizational performance and the extent to which enterprises can engage in an "honest" dialogue and share with stakeholders transparent information "without putting their competitive advantage at risk" [16].

\subsubsection{The Design and Commercialization of RIH through Social Entrepreneurship}

Social enterprises may include enterprising charities, cooperatives and social purpose for-profit businesses (with limitations on profit distribution). In practice, most of them are not-for-profit, collectively owned and do not have shareholders [55]. A review of the social entrepreneurship scholarship confirmed the existence of an emerging evidence base about the establishment and growth of social enterprises [64]. However, the extent to which social enterprises can support the design and commercialization of technology-based products and services remains ill understood.

While RRI emphasizes the importance of user-centered design and of technologies that are ethically and socially responsive to the context of adoption, when social enterprises seek to innovate "for society and with society", practical knowledge management appears particularly important [16]. For Stilgoe and colleagues [65], RRI is characterized by anticipation, reflexivity, inclusion and responsiveness. Burget et al. [66] add to these principles sustainability and care. All of these principles could help social entrepreneurs and their stakeholders to adopt design processes adapted to RIH. In theory, health innovations can either alleviate or exacerbate the challenges health systems are facing [67]. For instance, an effective health information system could support the production and use of reliable and timely evidence by service providers who cater to the same patient. At the same time, the implementation of such a new information system requires additional training and personnel, which may impact other areas of care [68]. Research on RIH should thus aim at clarifying the organizational capacity social enterprises need in order to design and commercialize technologies that apply the principles of RIH. This entails examining their governance, knowledge-based capabilities, resource mobilization and partnerships [56,64].

\subsubsection{The Unlocking of RIH by Social Finance}

Dambrin et al. [24] observed that pharmaceutical laboratories are under strong incentives to "replicate" more than "innovate" when growing margins of profit have to be measured and reported to shareholders. The overreliance on venture capital subjugates innovation to financial speculation, prioritizing value extraction, i.e., generating profits, over value creation, i.e., providing a valuable health product [19]. As a result, the purpose behind the creation of innovative companies "is not to substantially improve health as much as to provide a temporary vehicle for generating returns on investment" [21]. 
Scholars should thus turn their attention to social finance (or impact investing), which refers to "the active investment of capital in businesses and funds that generate positive social and/or environmental impacts, as well as financial returns" to the investor [57]. Social finance greatly differs from philanthropy since it consists in "the application of tools, instruments and strategies where capital" is deliberately and intentionally put to the service of social and economic returns $[59,69]$. According to the Canadian Task Force on Social Finance [57], impact investing could reach 1\% of all managed US assets and a comparable shift in Canada "would yield \$30B for investment in social enterprises". Although this form of financing is rapidly growing and could leverage responsible innovation, the ability of social finance to unlock RIH has not been examined. Social finance may offer the more "patient" and long-term financial support that small firms need to engage in R\&D activities and bring to market responsible innovations. Since financial viability remains a key issue for socially-oriented ventures, scholars have begun to examine what represents a fair level of profit for social enterprises such as microfinance institutions [70]. Scholars could further examine under what conditions the governance and accountability frameworks [69] of social finance may support the design and commercialization of RIH. For instance, if a venture were to develop cyber-therapies for patients afflicted by chronic mental illnesses, it would entail identifying how the long-term social and economic returns are estimated and which milestones are used to measure progress.

\subsection{Areas for Further Reflections}

\subsubsection{The Need for Innovation within Innovation}

We began this paper by quoting the multi-stakeholder report of the Economic and Social Council of the UN, which highlighted that the 2030 Agenda for Sustainable Development implies "a radical departure from business as usual" [1]. Nonetheless, the STI vision laid out in this report evokes a rather classical technology-push model wherein new technologies are seen as providing solutions to which societies must adapt. As Morlacchi and Martin [39] point out, the current STI model originates from a school of thought in economics that trusts market mechanisms and views the role of the State and public policymakers as one of facilitating market interactions and supporting a form of self-regulating collective process among firms. Current scholarship tends to emphasize the extent to which this model cannot handle complex STI policy matters such as sustainable development $[16,53,54]$. To support social and economic inclusion and promote environmental sustainability around the world, we believe that a more radical STI model is needed. Likewise, the UN Economic and Social Commission for Asia and the Pacific argued that the "most critical shift" required to meet the ambitions of the 2030 Agenda lies with the integration of the "people, planet and prosperity" elements of sustainable development "in and through" STI policy [2].

We thus concur with Roy and King [27] for whom "what we ultimately need is innovation in innovation": without a transformation of the established profit-driven and financialized STI approach, inequitable and unsustainable health systems could result in deleterious impacts on the SDGs. Many new products of the biotechnology revolution "are bound to be more expensive than the technologies they replace" and are likely to be "owned by commercial enterprises, allowing monopoly prices to be charged for them until the patents expire" [5]. Although third-party payers in different countries could, together, negotiate with companies to "force prices down towards the costs of production", these companies would argue that it undermines incentives to innovate [5]. They would not be entirely wrong considering that steady growth and increasing profit margins are what they need to thrive on financial markets. However, this argument only makes sense in the current, highly financialized STI approach, which pushes away from the kind of STI that is needed to support RIH and the SDGs.

Of course, a wholehearted belief in social entrepreneurship could be rightly criticized as overly naive. Yet, as aptly put by Auerswald [60], it would be equally naive to trust the transformative power of governments, international organizations and multinational corporations. While there is widespread agreement that governments around the world should actively support STI to tackle societal 
challenges, providing "comprehensive solutions" to problems that are global and interconnected "exceeds the capacity of single states or market forces alone" [12]. Likewise, Hajer and colleagues called "cockpit-ism" the "illusion that top-down steering by governments and intergovernmental organizations alone can address global problems" [71].

Hence, it is important to further reflect on the way responsible innovation may thrive under the collective action of inclusive and locally governed institutions that can cooperate on the basis of a clear definition of what a sustainable utilization of resources from the commons entails (e.g., land, water, air, etc.). For Forsyth and Johnson [52], systems characterized by multiple governing authorities at differing scales (e.g., community, firm, municipalities, trade association, etc.) have an important bearing on the way resources are shared, protected, renewed and distributed. If one mainly views the "strategic behaviour and rhetoric" of politicians and policymakers who prefer to avoid taking responsibility (and subsequent blame) for controversial decisions [39], one may easily conclude that research on responsible innovations will remain of marginal value to STI policymakers. Alternatively, if one posits policymakers as "reflexive practitioners" who are eager to share their own expertise with researchers and improve how the government serves citizens' interests [72], the scaling up of responsible innovations may proceed more swiftly. Overall, scholars and policymakers need to reflect on the large-scale partnerships that can transform how different countries address SDGs at the local scale.

\subsubsection{Responsibility in the Practice of (Social) Entrepreneurs}

For Stahl and colleagues, "when understood as a meta-responsibility, the role of RRI is to shape, maintain, develop, coordinate and align" STI processes, actors and responsibilities [15]. Yet, these authors stress that the private sector represents a "missing central concept" in RRI. For Hajer and colleagues, since business plays a key role in sustainable development, it needs to be "held more directly accountable" and policy incentives targeted at innovative entrepreneurs could be deployed wisely, that is, as a means to affect the rules of the game [71]. For instance,

Targets on sustainable production and resource efficiency that directly address businesses will not only support front runners in developing sustainable business models but will also put pressure on laggards to change unsustainable corporate practices [71].

Lubberink and colleagues found that companies involved in responsible innovation tend to involve stakeholders who share similar values and are motivated to align their interests with the shared objective of the innovation, while avoiding those holding conflicting values or who might oppose the innovation [16]. This tendency could also characterize social entrepreneurship. Scholars should thus reflect on the challenges raised by the operationalization of RRI in different entrepreneurial contexts, which may include a "selective openness" when sharing information and a tendency to maintain power over the innovation process [16].

Notwithstanding the multifaceted and controversial role of the private sector in sustainable development [13], entrepreneurs, be they socially-oriented or not, are increasingly affected by a shifting corporate culture, which may influence how they perceive the value of sustainable innovation. Ait Sidhoum and Serra [73], who studied global firms, observed a positive link between economic and environmental performance, pointing out that the business community has been able to make these two dimensions "complementary rather than substitutional". Their findings suggest that "effective reduction of pollution and promotion of social welfare" positively affects employee satisfaction and retention as well as consumers' loyalty. Hence, STI policies that foster the development of sustainable innovation may benefit from broad public support.

\subsection{Strenghts and Limitations of This Study}

There are limitations inherent to an exploratory study like ours. First, the lack of both theoretical and empirical studies on RIH and the SDGs implies that our findings cannot be directly confronted to an existing, well-defined body of knowledge. Second, our web-based horizon scanning strategy 
cannot be straightforwardly reproduced: innovative companies disappear as quickly as new ones emerge, digital contents change rapidly and social media platforms yield results that vary across users, space and time [42]. Third, our dataset is limited to innovations that were described in at least one of the languages spoken by our research team members (English, French, Portuguese and Spanish) and thus exclude innovations from a large part of the world. One should particularly keep in mind the innovative capacities of Asian countries that our sample failed to capture. Despite these limitations, our study establishes the groundwork needed to begin a more systematic examination of how innovations possessing responsibility features may help to address various SDGs.

\section{Conclusions}

Since the late 1980s, technological advances in health have been accompanied by both hope and hype. Often driven by rich countries, STI have overpromised, typically neglecting the commercial and financial dynamics that make it impossible for poor countries to obtain the benefits of these advances. For instance, hype characterized the human genome project since its beginnings as "deciphering the genetic make-up of new or resurgent infectious diseases such as AIDS, malaria and tuberculosis" could lead to new ways of eliminating them [5]. Perhaps it is true that it may technically happen, but current economic and political arrangements make the claim extremely weak: Neither the problem nor the solution is simply a technological matter.

Because certain types of innovation are more likely than others to help tackle the intractable problems of health systems, it is important to clarify the mechanisms by which a different STI approach can address the needs of a growing population, support patients who are afflicted by chronic diseases and reduce health disparities. Such research bears implications for entrepreneurs and policymakers worldwide as it can generate the knowledge needed for each country to achieve greater social and economic benefits. This paper thus sought to contribute the groundwork that may lead to a better understanding of how RIH responds to the call for new ways of interfacing society and STI in the pursuit of the SDGs.

Author Contributions: All four authors conceived the paper. P.L. wrote the first draft of the manuscript and H.P.S. supervised data collection and analysis. H.P.S., R.P. and F.R. reviewed and edited the manuscript and approved the final version.

Funding: This research was funded by the Canadian Institutes of Health Research (CIHR; \#FDN-143294). The first author holds a University of Montreal Chair on Responsible Innovation in Health (2015-18). Our research group infrastructure is supported by the Fonds de la recherche en santé du Québec (FRQ-S).

Acknowledgments: This paper draws on work conducted within the In Fieri research program (www.infieri. umontreal.ca). We thank members of our research team who provided us with useful information and shared insightful comments: Catherine Beaudry, Jérémy Bouchez, Geneviève Daudelin Jean-Louis Denis, Philippe Gauthier, Dominique Grimard, Nicola Hagemeister, Réjean Hébert, William Lazonick, Marguerite Mendell, Fiona A. Miller, Xavier Pavie, Patrick Vachon and Andrew Webster. We thank Andrée-Anne Lefebvre for her assistance with the social media horizon scanning project.

Conflicts of Interest: The authors declare no conflict of interest. The funders of the study had no role in the design of the study; in the collection, analyses, or interpretation of data; in the writing of the manuscript, or in the decision to publish the results.

\section{References}

1. UNESCO. Multi-stakeholder forum on science, technology and innovation for the sustainable development goals: Summary by the co-chairs. In High-Level Political Forum on Sustainable Development, Convened under the Auspices of the Economic and Social Council, 11-20 July 2016; United Nations Economic and Social Council: New York, NY, USA, 2016.

2. UNESCO. Science, Technology and Innovation for Sustainable Development, Economic and Social Commission for Asia and the Pacific Bangkok, 15-19 May 2016; United Nations Economic and Social Council: New York, NY, USA, 2016.

3. OECD. New Health Technologies: Managing Access, Value and Sustainability; OECD Publishing: Paris, France, 2017. 
4. WHO. Medical Devices: Managing the Mismatch: An Outcome of the Priority Medical Devices Project; World Health Organization: Geneva, Switzerland, 2010.

5. Hurst, J. Challenges for health systems in member countries of the organisation for economic co-operation and development. Bull. World Health Organ. 2000, 78, 751-760. [PubMed]

6. Halfon, N.; Conway, P.H. The opportunities and challenges of a lifelong health system. N. Engl. J. Med. 2013, 368, 1569-1571. [CrossRef] [PubMed]

7. Fong, H.; Harris, E. Technology, innovation and health equity. Bull. World Health Organ. 2015, 93, 438. [CrossRef] [PubMed]

8. Demers-Payette, O.; Lehoux, P.; Daudelin, G. Responsible Research and Innovation: A productive model for the future of medical innovation. J. Responsib. Innov. 2016, 3, 188-208. [CrossRef]

9. Silva Pacifico, H.; Lehoux, P.; Miller, F.A.; Denis, J.-L. Introducing Responsible Innovation in Health: A policy-oriented framework. Health Res. Policy Syst. 2018, 16, 90. [CrossRef] [PubMed]

10. Lubberink, R.; Blok, V.; van Ophem, J.; Omta, O. A framework for Responsible Innovation in the business context: Lessons from responsible-, social-and sustainable innovation. In Responsible Innovation 3; Springer: New York, NY, USA, 2017; pp. 181-207.

11. Klaassen, P.; Kupper, F.; Rijnen, M.; Vermeulen, S.; Broerse, J. Policy brief on the state of the art on RRI and a working definition of RRI. In RRI Tools: Fostering Responsible Research and Innovation; Athena Institute: Amsterdam, The Netherlands, 2014. Available online: https:/ / www.rri-tools.eu/documents/10184/107098/ RRITools_D1.1-RRIPolicyBrief.pdf/c246dc97-802f-4fe7-a230-2501330ba29b (accessed on 1 November 2018).

12. Nilsson, A. Making norms to tackle global challenges: The role of intergovernmental organisations. Res. Policy 2017, 46, 171-181. [CrossRef]

13. Spangenberg, J.H. Hot air or comprehensive progress? A critical assessment of the SDGs. Sustain. Dev. 2017, 25, 311-321. [CrossRef]

14. Hin, G.; Daigney, M.; Haudebault, D.; Raskin, K.; Bouche, Y.; Pavie, X.; Carthy, D. Introduction to a Guide to Entrepreneurs and Innovation Support Organizations. EU Funded Project Report by Paris Region Enterprises and Knowledge Acceleration Responsible Innovation Meta (KARIM) Network. 2014. Available online: https:/ / www.inclusilver.eu/wp-content/uploads/2017/09/INCluSilver-InnovationSupportServicesHandbook.pdf (accessed on 1 November 2018).

15. Stahl, B.C.; Obach, M.; Yaghmaei, E.; Ikonen, V.; Chatfield, K.; Brem, A. The Responsible Research and Innovation (RRI) maturity model: Linking theory and practice. Sustainability 2017, 9, 1036. [CrossRef]

16. Lubberink, R.; Blok, V.; van Ophem, J.; Omta, O. Lessons for Responsible Innovation in the business context: A systematic literature review of responsible, social and sustainable innovation practices. Sustainability 2017, 9, 721. [CrossRef]

17. Auer, A.; Jarmai, K. Implementing Responsible Research and Innovation practices in SMEs: Insights into drivers and barriers from the Austrian medical device sector. Sustainability 2017, 10, 17. [CrossRef]

18. Hopkins, M.; Lazonick, W. Who Invests in the High-Tech Knowledge Base? Institute for New Economic Thinking, Working Group on the Political Economy of Distribution, The Academic-Industry Research Network: Cambridge, MA, USA, 2014. Available online: http:/ /www.theairnet.org/v3/backbone/uploads/2014/05/ AIR-WP14.0901_Hopkins_Lazonick_High-TechKnowledgeBase.pdf (accessed on 1 November 2018).

19. Lazonick, W.; Mazzucato, M. The risk-reward nexus in the innovation-inequality relationship: Who takes the risks? Who gets the rewards? Ind. Corp. Chang. 2013, 22, 1093-1128. [CrossRef]

20. Lehoux, P.; Daudelin, G.; Williams-Jones, B.; Denis, J.-L.; Longo, C. How do business model and health technology design influence each other? Insights from a longitudinal case study of three academic spin-offs. Res. Policy 2014, 43, 1025-1038. [CrossRef]

21. Lehoux, P.; Miller, F.; Daudelin, G.; Urbach, D. How venture capitalists decide which new medical technologies come to exist. Sci. Public Policy 2015, 43, 375-385. [CrossRef]

22. Radjou, N. Frugal Innovation: The Engine of Sustainable Development. How to Achieve Better Healthcare for More People at Lower Cost. 2015. Available online: http://ic2030.org/2015/07/frugal-innovation/ (accessed on 1 November 2018).

23. Fineberg, H.V. A successful and sustainable health system-How to get there from here. N. Engl. J. Med. 2012, 366, 1020-1027. [CrossRef] [PubMed]

24. Dambrin, C.; Lambert, C.; Sponem, S. Control and change-Analysing the process of institutionalisation. Manag. Account. Res. 2007, 18, 172-208. [CrossRef] 
25. Lehoux, P.; Roncarolo, F.; Rocha Oliveira, R.; Pacifico Silva, H. Medical innovation and the sustainability of health systems: A historical perspective on technological change in health. Health Serv. Manag. Res. 2016, 29, 115-123. [CrossRef]

26. Gardner, C.A.; Acharya, T.; Yach, D. Technological and social innovation: A unifying new paradigm for global health. Health Aff. 2007, 26, 1052-1061. [CrossRef] [PubMed]

27. Roy, V.; King, L. Betting on hepatitis c: How financial speculation in drug development influences access to medicines. BMJ Br. Med. J. 2016, 354. [CrossRef] [PubMed]

28. Morhason-Bello, I.O.; Odedina, F.; Rebbeck, T.R.; Harford, J.; Dangou, J.M.; Denny, L.; Adewole, I.F. Challenges and opportunities in cancer control in Africa: A perspective from the african organisation for research and training in cancer. Lancet Oncol. 2013, 14, e142-151. [CrossRef]

29. Pramesh, C.S.; Badwe, R.A.; Borthakur, B.B.; Chandra, M.; Raj, E.H.; Kannan, T.; Kalwar, A.; Kapoor, S.; Malhotra, H.; Nayak, S.; et al. Delivery of affordable and equitable cancer care in India. Lancet Oncol. 2014, 15, e223. [CrossRef]

30. Charlton, M.; Schlichting, J.; Chioreso, C.; Ward, M.; Vikas, P. Challenges of rural cancer care in the United States. Oncology 2015, 29, 633-640. [PubMed]

31. Macdonnell, M.; Darzi, A. A key to slower health spending growth worldwide will be unlocking innovation to reduce the labor-intensity of care. Health Aff. 2013, 32, 653-660. [CrossRef] [PubMed]

32. Strezov, V.; Evans, A.; Evans, T.J. Assessment of the economic, social and environmental dimensions of the indicators for sustainable development. Sustain. Dev. 2017, 25, 242-253. [CrossRef]

33. Grimaldi, R.; Kenney, M.; Siegel, D.S.; Wright, M. 30 years after bayh-dole: Reassessing academic entrepreneurship. Res. Policy 2011, 40, 1045-1057. [CrossRef]

34. Faria, A.P.; Barbosa, N. Does venture capital really foster innovation? Econ. Lett. 2014, 122, 129-131. [CrossRef]

35. Chen, L. The most profitable industries in 2016. Forbes, 21 December 2015.

36. Lehoux, P.; Miller, F.A.; Daudelin, G.; Denis, J.L. Providing value to new health technology: The early contribution of entrepreneurs, investors, and regulatory agencies. Int. J. Health Policy Manag. 2017, 6, 509-518. [CrossRef] [PubMed]

37. Levänen, J.; Hossain, M.; Lyytinen, T.; Hyvärinen, A.; Numminen, S.; Halme, M. Implications of frugal innovations on sustainable development: Evaluating water and energy innovations. Sustainability 2015, 8, 4. [CrossRef]

38. Colquitt, J.A.; Zapata-Phelan, C.P. Trends in theory building and theory testing: A five-decade study of the academy of management journal. Acad. Manag. J. 2007, 50, 1281-1303. [CrossRef]

39. Morlacchi, P.; Martin, B.R. Emerging Challenges for Science, Technology and Innovation Policy Research: A Reflexive Overview; Elsevier: Amsterdam, The Netherlands, 2009.

40. Amanatidou, E.; Butter, M.; Carabias, V.; Könnölä, T.; Leis, M.; Saritas, O.; Schaper-Rinkel, P.; van Rij, V. On concepts and methods in horizon scanning: Lessons from initiating policy dialogues on emerging issues. Sci. Public Policy 2012, 39, 208-221. [CrossRef]

41. Douw, K.; Vondeling, H.; Eskildsen, D.; Simpson, S. Use of the Internet in scanning the horizon for new and emerging health technologies: A survey of agencies involved in horizon scanning. J. Med. Internet Res. 2003, 5. [CrossRef] [PubMed]

42. Bennato, D.; Rossi, L.; Giglietto, F. The open laboratory: Limits and possibilities of using Facebook, Twitter, and Youtube as a research data source. In Methods for Analyzing Social Media; Routledge: London, UK, 2017; pp. 19-33.

43. Palomino, M.A.; Bardsley, S.; Bown, K.; De Lurio, J.; Ellwood, P.; Holland-Smith, D.; Huggins, B.; Vincenti, A.; Woodroof, H.; Owen, R. Web-based horizon scanning: Concepts and practice. Foresight 2012, 14, 355-373. [CrossRef]

44. Cammack, V.; Byrne, K. Accelerating a network model of care: Taking a social innovation to scale. Technol. Innov. Manag. Rev. 2012, 2, 26. [CrossRef]

45. Umberson, D.; Karas Montez, J. Social relationships and health: A flashpoint for health policy. J. Health Soc. Behav. 2010, 51, S54-S66. Available online: http://journals.sagepub.com/doi/abs/10.1177/ 0022146510383501 (accessed on 1 November 2018). [CrossRef] [PubMed]

46. Howard, C.; Rose, C.L.; Trouton, K.; Stamm, H.; Marentette, D.; Kirkpatrick, N.; Karalic, S.; Fernandez, R.; Paget, J. Flow (finding lasting options for women): Multicentre randomized controlled trial comparing tampons with menstrual cups. Can. Fam. Phys. 2011, 57, e208-e215. 
47. Sundqvist, J. A Cup of Freedom?: A Study of the Menstrual Cup's Impact on Girls' Capabilities; Linnaeus University: Växjö, Sweden, 2015.

48. WEN. Seeing Red-Sanitary Protection \& the Environment, Briefing; Women's Environment Network (WEN): London, UK, 2012. Available online: https:/ / static1.squarespace.com/static/559d276fe4b0a65ec3938057/t/ 560d0280e4b079cb072e979e/1443693184604/environmenstrualweb14.pdf (accessed on 1 November 2018).

49. Pozelli, R. Une Innovation Qui Donne de la Voix! Blogue Hinnovic. 2017. Available online: http: / / www. hinnovic.org/solar-ear-une-innovation-qui-donne-de-la-voix/ (accessed on 20 October 2018).

50. Whitmee, S.; Haines, A.; Beyrer, C.; Boltz, F.; Capon, A.G.; de Souza Dias, B.F.; Ezeh, A.; Frumkin, H.; Gong, P.; Head, P. Safeguarding human health in the anthropocene epoch: Report of the Rockefeller Foundation-Lancet Commission on planetary health. Lancet 2015, 386, 1973-2028. [CrossRef]

51. Prime, M.; Attaelmanan, I.; Imbuldeniya, A.; Harris, M.; Darzi, A.; Bhatti, Y. From Malawi to Middlesex: The case of the arbutus drill cover system as an example of the cost-saving potential of frugal innovations for the UK NHS. BMJ Innov. 2018, 4, 103-110. [CrossRef]

52. Forsyth, T.; Johnson, C. Elinor ostrom's legacy: Governing the commons and the rational choice controversy. Dev. Chang. 2014, 45, 1093-1110. [CrossRef]

53. Bohnsack, R.; Pinkse, J.; Kolk, A. Business models for sustainable technologies: Exploring business model evolution in the case of electric vehicles. Res. Policy 2014, 43, 284-300. [CrossRef]

54. Boons, F.; Lüdeke-Freund, F. Business models for sustainable innovation: State-of-the-art and steps towards a research agenda. J. Clean. Prod. 2013, 45, 9-19. [CrossRef]

55. Mendell, M. Reflections on the evolving landscape of social enterprise in North America. Policy Soc. 2010, 29, 243-256. [CrossRef]

56. Weerawardena, J.; Mort, G.S. Investigating social entrepreneurship: A multidimensional model. J. World Bus. 2006, 41, 21-35. [CrossRef]

57. Canadian Task Force on Social Finance. Mobilizing Private Capital for Public Good. 2010. Available online: https:/ / www.marsdd.com/mars-library/mobilizing-private-capital-for-public-good-canadiantask-force-on-social-finance/ (accessed on 20 October 2018).

58. Abu-Saifan, S. Social entrepreneurship: Definition and boundaries. Technol. Innov. Manag. Rev. 2012, 2, $22-27$. [CrossRef]

59. Emerson, J. The blended value proposition: Integrating social and financial returns. Calif. Manag. Rev. 2003, 45, 35-51. [CrossRef]

60. Auerswald, P. Creating Social Value. Stanford Social Innovation Review. 2009; pp. 51-55. Available online: https:/ / ssir.org/articles/entry/creating_social_value (accessed on 1 November 2018).

61. Chesbrough, H.; Rosenbloom, R.S. The role of the business model in capturing value from innovation: Evidence from Xerox Corporation's technology spin-off companies. Ind. Corp. Chang. 2002, 11, 529-555. [CrossRef]

62. Demil, B.; Lecocq, X. Business model evolution: In search of dynamic consistency. Long Range Plan. 2010, 43, 227-246. [CrossRef]

63. Wirtz, B.W.; Pistoia, A.; Ullrich, S.; Göttel, V. Business models: Origin, development and future research perspectives. Long Range Plan. 2016, 49, 36-54. [CrossRef]

64. Doherty, B.; Haugh, H.; Lyon, F. Social enterprises as hybrid organizations: A review and research agenda. Int. J. Manag. Rev. 2014, 16, 417-436. [CrossRef]

65. Stilgoe, J.; Owen, R.; Macnaghten, P. Developing a framework for responsible innovation. Res. Policy 2013, 42, 1568-1580. [CrossRef]

66. Burget, M.; Bardone, E.; Pedaste, M. Definitions and conceptual dimensions of Responsible Research and Innovation: A literature review. Sci. Eng. Ethics 2017, 23, 1-19. [CrossRef] [PubMed]

67. Van Olmen, J.; Criel, B.; Van Damme, W.; Marchal, B.; Van Belle, S.; Van Dormael, M.; Hoerée, T.; Pirard, M.; Kegels, G. Analysing health systems to make them stronger. Stud. Health Serv. Organ. Policy 2010, 27, 2-98.

68. Roncarolo, F.; Boivin, A.; Denis, J.-L.; Hébert, R.; Lehoux, P. What do we know about the needs and challenges of health systems? A scoping review of the international literature. BMC Health Serv. Res. 2017, 17, 636. [CrossRef] [PubMed]

69. Antadze, N.; Westley, F.R. Impact metrics for social innovation: Barriers or bridges to radical change? J. Soc. Entrep. 2012, 3, 133-150. [CrossRef] 
70. Hudon, M.; Labie, M.; Reichert, P. What is a fair level of profit for social enterprise? Insights from microfinance. J. Bus. Ethics 2018, 1-18. [CrossRef]

71. Hajer, M.; Nilsson, M.; Raworth, K.; Bakker, P.; Berkhout, F.; de Boer, Y.; Rockström, J.; Ludwig, K.; Kok, M. Beyond cockpit-ism: Four insights to enhance the transformative potential of the sustainable development goals. Sustainability 2015, 7, 1651-1660. [CrossRef]

72. Vuong, Q.-H. The (ir) rational consideration of the cost of science in transition economies. Nat. Hum. Behav. 2018, 2, 5. [CrossRef]

73. Ait Sidhoum, A.; Serra, T. Corporate sustainable development. Revisiting the relationship between corporate social responsibility dimensions. Sustain. Dev. 2018, 26, 365-378. [CrossRef]

2018 by the authors. Licensee MDPI, Basel, Switzerland. This article is an open access article distributed under the terms and conditions of the Creative Commons Attribution (CC BY) license (http://creativecommons.org/licenses/by/4.0/). 